\title{
Expression of Human Neutrophil Gelatinase-Associated Lipocalin (Ngal) on Serum and Urine Sample of Pre Dialysis Kidney Failure Patients
}

\author{
Retty Ratnawati ${ }^{1 *}$, Tinny Endang Hernowati ${ }^{2}$, Nurina Titisari ${ }^{3}$, Ahmad Fauzi $^{4}$ \\ ${ }^{1,2}$ Faculty of Medicine, University of Brawijaya., Indonesia \\ ${ }^{3,4}$ Faculty of Veterinary Medicine, University of Brawijaya. Malang, Indonesia
}

Corresponding author: rettyrst@yahoo.co.id, rettyr.fk@ub.ac.id

\begin{abstract}
Biomarkers for the early prediction of human acute kidney injury (AKI) are clinically important. Recently, neutrophil gelatinase-associated lipocalin (NGAL) has found to be a sensitive biomarker for the prediction of human AKI at a very early stage and the development of AKI after surgery. NGAL is an accurate biosensor to determine kidney function, previous studies have mentioned that NGAL biomarker has been detected in patients with renal failure post cardiac surgery, kidney transplants, and septicemia shock. Therefore the objective of this study is to evaluate the expression of NGAL in serum and urine sample of patients with predialysis renal failure.We collected 10 samples of patients predialysis in Saiful Anwar Hospital which were indicated kidney failure. Then NGAL protein expression was evaluated by SDS PAGE and verified by western blot method. Urea and creatinine serum were analyzed by spectrophotometer method. The data obtained were analyzed descriptively. The results showed that in 10 patients with renal failure predialysis have shown an increase of serum BUN and creatinine above normal. Serum and urine samples of patients were examined by polyacrylamide gel electrophoresis method by a thick protein bands at $25 \mathrm{kDa}$. While the western blot of NGAL showed positive results expressed by NGAL protein in the samples. In conclusion, the NGAL protein was detected in predialysis patients.
\end{abstract}

Keywords: Human Neutrophil gelatinase-associated lipocalin (NGAL), Kidney Failure, Predialisa, SDS PAGE, Westernblot

\section{INTRODUCTION}

AKI incidence in humans has been reported to cause complications $1-7 \%$ in hospitalized patients and $1-25 \%$ in the intensive care unit ${ }^{1}$. Over the past 50 years, the mortality rate of patients with AKI in intensive care unit (ICU) still high at about 50-70\%, the incidence of AKI has increased greatly over time ${ }^{2}$. The cause of frequent cases of AKI are ischemic events and toxicity due to sepsis, a blood cancer or immunodeficiency syndrome. In addition, cases of AKI can also be caused by many conditions, such as reduction in renal perfusion or intrarenal, poisoning or obstruction (blockage) in the renal tubules, tubulointerstitial inflammation and edema, or decrease in glomerular filtration capability ${ }^{3}$.

The recent discovery, translation and validation of neutrophil gelatinase-associated lipocalin (NGAL), possibly the most promising novel AKI biomarker. Neutrophil gelatinaseassociated lipocalin (NGAL), found in activated neutrophils is a protein belonging to the lipocalin superfamily that initially an agent which acts as bacteriostatic However, later pointed out that many cell types, including renal tubules, can produce NGAL in response to various injuries ${ }^{4}$. NGAL levels could be increased in some systemic diseases not necessarily 
associated with infective processes, confirming that many other tissues may release NGAL as an acute-phase factor signaling a condition of sustained injury 5 .

\section{MATERIAL AND METHOD}

Screening patients with acute renal failure performed by following the predetermined standard by the Acute Kidney Injury Network (AKIN) organization ie, acute renal failure occurs when there is a decline in kidney function (within 48 hours) which seen at the increase in serum creatinine $\geq 0.3 \mathrm{mg} / \mathrm{dL}$ or an increase in the percentage of creatinine $\geq 50 \%$, or decreased urine output (oliguria indicated that urine $<0.5 \mathrm{~mL} / \mathrm{kg} / \mathrm{hr}$ for $>6$ hours). The results of this study, 10 samples of urine and blood of patients were diagnosed as AKI.

Stages of research were the isolation of protein from urine and blood sample using SDS page method to Monitoring NGAL protein molecular weight. Urine and serum sampel analyze with Western Blot human NGAL Antibody (Santacrus). Urea and serum creatinine are measured using spectrophotometry methods. The data obtained were analyzed descriptively.

\section{RESULT AND DISCUSSION}

The Mean level of urea and creatinine in 10 patients kidney failure that was $132 \mathrm{mg} /$ $\mathrm{dL}$ and $4.8 \mathrm{mg} / \mathrm{dL}$. Levels of reference values for urea and creatinine examination was 15-21 $\mathrm{mg} / \mathrm{dL}$ and 0.20-0.80 mg / dL. Creatinine levels in kidney failure stands at> $3 \mathrm{mg} / \mathrm{dL}$ so that the pre hemodialysis patients has shown the occurrence of renal failure.

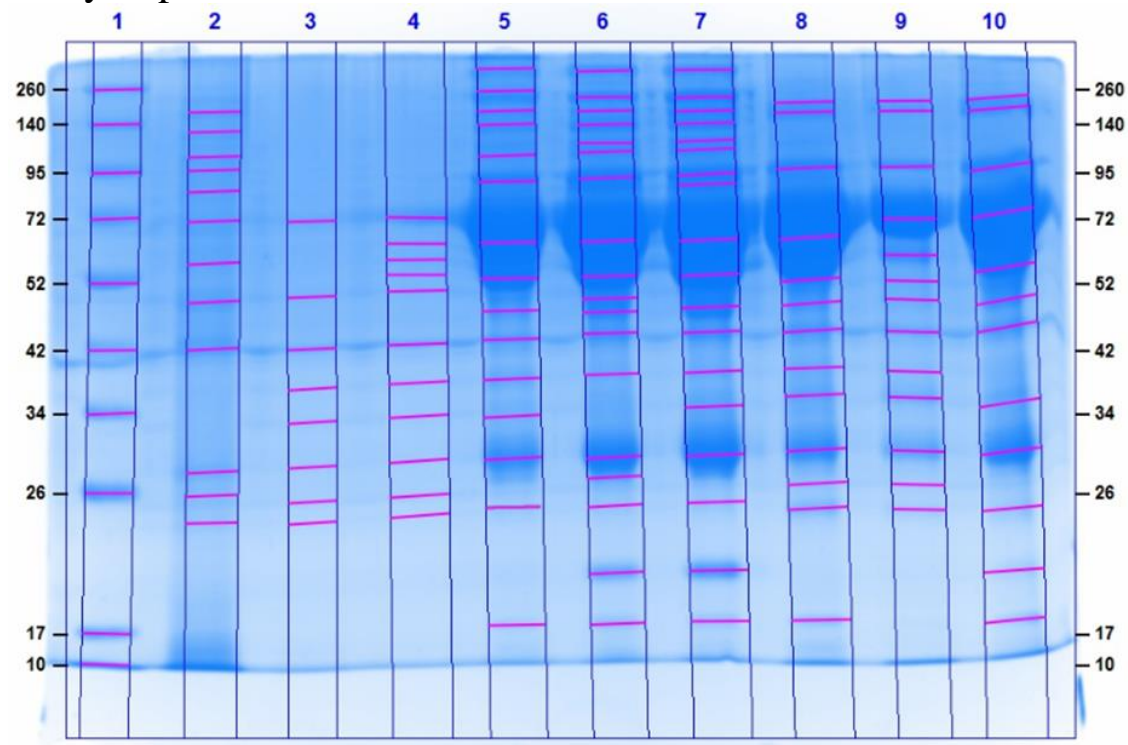

Figure 1. Results of SDS PAGE electrophoresis blood and urine samples of renal failure pre-hemodialysis patients. Description: 1: Marker, 2-6: urine, 7-10: Serum

NGAL accumulates in the blood, urine, renal proximal and distal renal tubular damage $^{6}$. Electrophoresis results from urine and plasma samples of patients with renal failure pre-haemodialysis showed some proteins with diffential molecular weights (Figure 1). Whereas the target molecular weight of NGAL protein in this study was $25 \mathrm{kDa}$. Neutrophil gelatinase-associated lipocalin (NGAL) is a $25-\mathrm{kDa}$ protein that is expressed during kidney damage ${ }^{7}$. NGAL protein increased 100 times in humans response to renal tubular injury, and occurs a rapid increase in urine and serum useful as an early biomarker of renal failure ${ }^{8}$. So it is possible ahead of urine NGAL protein can be used as a non-invasive biomarker of AKI. SDS PAGE sample results and then proceed to test western blot to ensure that the protein 
with a molecular weight of $25 \mathrm{kDa}$ protein NGAL is valid. The results indicate a bond wasternblot antibodies and antigen derived from serum and urine of patients with AKI (Figure 2). The results of this study should be continued quantitative testing, one of them with elisa test so that we can determine the extent to which differences in the expression of NGAL in urine and serum.

Early detection and treatment of kidney disease can result in preventing kidney disease progression. Thus, an early biomarker of kidney damage which can identify patients at an increased risk of disease progression would be helpful in kidney disease diagnosis and treatment. ${ }^{9}$ Since creatinine is not a sensitive marker of kidney function and eGFR also has some limitations, there is a growing need to find an early marker of kidney damage, newer studies suggest that NGAL has the potential to be an ideal biomarker to detect early kidney damage in patients at risk. ${ }^{9}$

It is now widely accepted that NGAL protein is a true acute-phase factor that can be released by virtually almost every injured tissue, often becoming a marker of disease severity ${ }^{10}$. For instance, in subjects with chronic kidney disease, increased serum and urinary NGAL levels correlate with residual renal function ${ }^{5}$ and a single measurement of NGAL after treatments potentially detrimental to the kidney (e.g. contrast administration, cardiac surgery) becomes useful in the early prediction of incipient acute kidney injury ${ }^{11,12}$. In our sampel patients, we can speculate that, overall, the up-regulation of NGAL belongs to a wide panel of responses to the systemic inflammation associated with kidney function. As reported for several other cytokines, kidney failure can induce the release of NGAL, probably as a stress response $^{13}$.

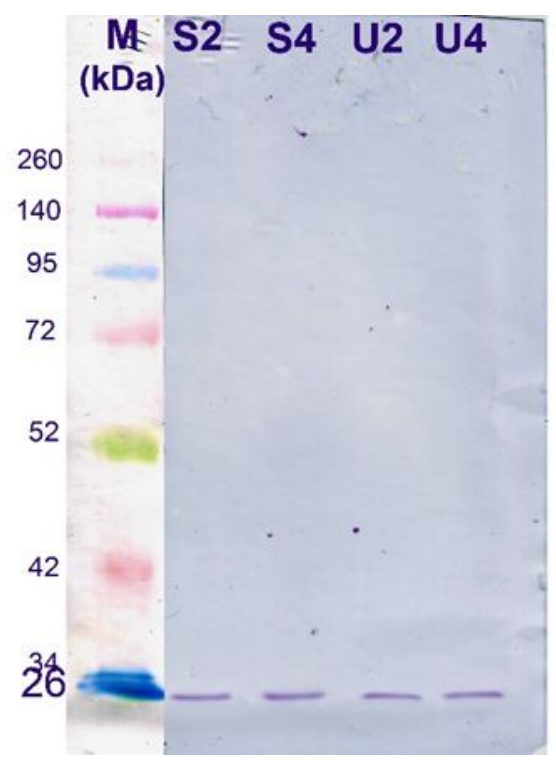

Figure 2. Results of Western Blot NGAL protein in the blood and urine samples of renal failure pre-hemodialysis patients. Description: M: Marker, S2-S4: Serum, U2-U4: urine.

\section{CONCLUSION}

The results of this study showed that in patients with renal failure showed an expression of NGAL in urine and blood samples. 


\section{REFERENCES}

1. de Mendonca, A., Vincent, J.L., Suter, P.M., Moreno, R., Dearden, N.M., Antonelli, M., Takala, J., Sprung, C., Cantraine, F., 2000. Acute renal failure in the ICU: risk factors and outcome evaluated by the SOFAscore. Intensive Care Med. 26, 915-921.

2. Waikar, S.S, Curhan, G.C., Wald, R., McCarthy E.P. and Chertow, G.M. 2006. Declining mortality in patients with acute renal failure 1988 to 2002. J. Am. Soc. Nephrol. 17:1143-1150.

3. Thadhani, R.M. and Boventre, J.V. 1996. Acute renal failure. N. Engl. J. Med. 334:14481460.

4. Goetz DH, Willie ST, Armen RS, Bratt T, Borregaard N, Strong RK: Ligand preference inferred from the structure of neutrophil gelatinase associated lipocalin. Biochemistry 39:1935-1941, 2000

5. Bolignano, D., Donato, V., Coppolino, G, Campo, S., Buemi, A., Lacquaniti, A., and Buemi, M. 2008. Neutrophil Gelatinase-Associated Lipocalin (NGAL) as a Marker of Kidney Damage. American Journal of Kidney Diseases, Vol 52, No 3 (September), pp 595-605

6. Mori, K., Lee, H.T., Rapoport, D., Drexler, I., Foster, K., Yang, J., Schmidt-Ott, Chen, X., Li, JY., Weiss, S., Mishra, J., Cheema, F.H., Markowitz, G., Suganami, T., Sawai, K., Mukoyama, M., Kunis, C., D'Agati, V., Devarajan, P. and Barasch, J. 2005. Endocytic delivery of lipocalin-siderophore-iron complex rescues the kidney from ischemia-reperfusion injury. J. Clin. Invest. 115:610-621.

7. Mishra, J., Mori, K., Ma, Q., Kelly, C., Barasch, J. and Devarajan, P. 2004. Neutrophil gelatinase-associated lipocalin (NGAL): A novel urinary biomarker for cisplatin nephrotoxicity. Am. J. Nephrol. 24:307-315.

8. Schmidt-Ott.K.M. 2011. Neutrophil gelatinase-associated lipocalin as a biomarker of acute kidney injury—where do we stand today?. Nephrol. Dial. Transpl. 26:762-764.

9. Barasch JM, Devarajan P, Nickolas TL, Mori K. Detection of NGAL in chronic renal disease. Google Patents US 8592170 B2; 2005.

10. Xu S, Venge P: Lipocalins as biochemical markers of disease. Biochim Biophys Acta 1482: 298-307, 2000

11. Shaikenov, B. T., 2004. Short Report the Use of Polymerase Chain Reaction to Detect Echinococcus granulosus (G1 strain) Eggs in Soil Samples. AM. J. Tropic.sd

12. Mishra J, Dent C, Tarabishi R. 2005. Neutrophil gelatinase-associated lipocalin (NGAL) as a biomarker for acute renal injury after cardiac surgery. Lancet; 365: 1231-1238

13. Jonsson P, Stahl ML, Ohlsson K. 1999. Extracorporeal circulation causes release of neutrophil gelatinase-associated lipocalin (NGAL). Mediators Inflamm. 8: 169-171 